
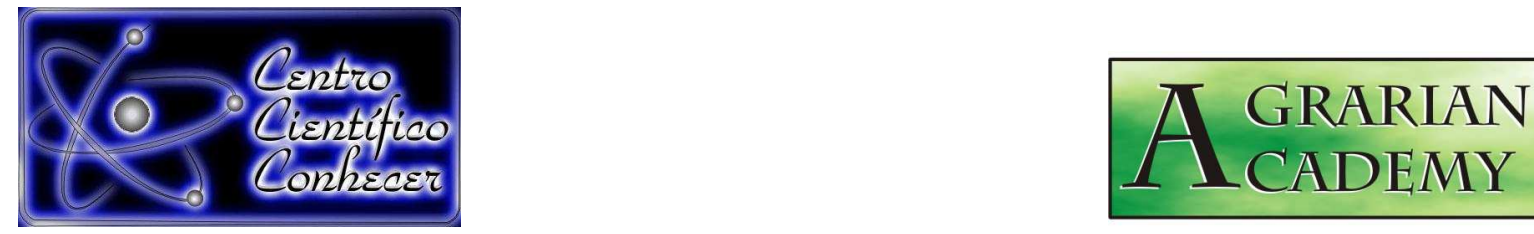

\title{
QUANTIFICAÇÃO E DISTRIBUIÇÃO ESPACIAL DOS CERTIFICADOS FLORESTAIS FSC NO BRASIL
}

Talita Walter dos Santos ${ }^{1}$, Allan Libanio Pelissari², Carlos Roberto Sanquetta ${ }^{3}$

1 Graduanda, Faculdade de Engenharia Florestal da Universidade Federal do

Paraná, Curitiba, Paraná, Brasil (talitawalter0@gmail.com)

2 Professor, Departamento de Ciências Florestais da Universidade Federal do

Paraná, Curitiba, Paraná, Brasil

3 Professor, Departamento de Ciências Florestais da Universidade Federal do

Paraná, Curitiba, Paraná, Brasil

Recebido em: 30/11/2017 - Aprovado em: 15/12/2017 - Publicado em: 31/12/2017 DOI: 10.18677/Agrarian Academy 2017b24

\section{RESUMO}

O presente trabalho teve como objetivo quantificar os certificados florestais FSC no Brasil e conhecer sua distribuição espacial com base nos relatórios de auditorias publicados no portal eletrônico do FSC. Os relatórios utilizados foram os mais atuais de cada empreendimento certificado válido até o ano de 2016. Para melhor visualização da distribuição espacial dos certificados criaram-se mapas. Há 1.099 certificados no Brasil distribuídos em três modalidades: manejo florestal (MF) com 6; manejo florestal e cadeira de custódia (MF/CoC) com 110; e cadeia de custódia (CoC) com 983 certificados. Sul e Sudeste são as regiões brasileiras com mais certificados, enquanto o Nordeste é a região com menos certificados. São Paulo é o estado com mais certificados, sendo a maioria na modalidade $\mathrm{CoC}$, seguido pelo Paraná, o qual destaca-se pela quantidade de certificados na modalidade $\mathrm{MF} / \mathrm{CoC}$, sendo todas de florestas plantadas. Os municípios que apresentam mais certificados FSC são os que tem vocação florestal, com economia dependente do setor ou com grandes empresas do ramo florestal instaladas em suas regiões.

PALAVRAS-CHAVE: certificação florestal, cadeia de custódia, manejo florestal.

\section{QUANTIFICATION AND SPACIAL DISTRIBUTION OF FSC FOREST CERTIFICATES IN BRAZIL}

\footnotetext{
ABSTRACT

The aim of this study was to quantify the FSC forest certificates in Brazil and to know their spatial distribution based on the audit reports published on the FSC website. The used reports were the most current of each certified enterprise valid until the year 2016. For better visualization of the spatial distribution of the certificates maps were created. There are 1,099 certificates in Brazil distributed in three modalities: forest management (MF) with 6; forest management and chain of custody (MF/CoC) with 110; and chain of custody $(\mathrm{CoC})$ with 983 certificates. South and Southeast are 
the most certified Brazilian regions, while the Northeast is the region with the lowest number of certificates. São Paulo is the state with the most certificates, being the majority in the CoC modality, followed by Paraná, which stands out for the quantity of certificates in the MF/CoC modality, all of them being planted forests. The municipalities that present the most FSC certificates are those with a forestry vocation, with an economy dependent on the forest sector or with big forestry companies located in their regions.

KEYWORDS: forest certification, forest management, chain of custody.

\section{INTRODUÇÃO}

A sustentabilidade é um tema abordado com muita frequência atualmente, sendo um dos maiores desafios da humanidade. Tomando em conta o conceito de sustentabilidade, que se aplica aos empreendimentos ou operações ecologicamente corretos, socialmente justos e economicamente viáveis, medidas foram criadas para alcançá-la. Nesse contexto, em 1992 ocorreu a Rio-92, reunião entre os chefes de estado para debater questões relacionadas ao meio ambiente, onde tornou-se evidente a importância de cada país em refletir sobre as questões ambientais (PEREIRA et al., 2017).

Assim, as certificações ambientais e florestais ganham importância para alcançar a sustentabilidade (PEREIRA et al., 2017). Segundo Sanquetta (2012), existia a necessidade de criar padrões, por meio de princípios e critérios, para servirem de roteiro para projetos cujo foco seja a aplicação do bom manejo florestal. Nesses moldes, são necessários empreendimentos adeptos a prática do manejo responsável por meio do cumprimento de padrões sustentáveis.

A certificação é um processo no qual uma entidade independente de terceira parte avalia se um determinado produto atende às normas técnicas, para, posteriormente, possibilitar o uso de um selo que ateste o cumprimento de padrões exigidos. Dentro do setor florestal, a certificação tem se desenvolvido desde a década de 1980 por meio de alguns sistemas em operação (ALVES et al., 2011), como o Forest Stewardship Council (FSC) e o Programme for the Endorsement of Forest (PEFC).

O FSC foi fundado em 1993 e credita certificadoras em todo o mundo para seguirem padrões de qualidade fundamentados em princípios e critérios da organização (ALVES et al., 2011; PAIVA et al., 2015; VIEIRA; MELO, 2017). Com isso, o FSC é o sistema de certificação mais aplicado no Brasil em três modalidades: manejo florestal (MF), cadeia de custódia (CoC) e madeira controlada (MC).

A certificação de manejo florestal garante que a floresta é manejada de forma responsável (AHRENS; OLIVEIRA, 2017). A certificação de cadeia de custódia garante a rastreabilidade desde a produção da matéria-prima das florestas até o consumidor final, ao passo que a madeira controlada tem como objetivo orientar as empresas certificadas a evitarem produtos com origem florestal de categorias consideradas inaceitáveis pelo FSC, como, por exemplo, madeira originária de desmatamento ilegal (FSC, 2017).

A madeira controlada não garante o "selo verde" ao produto florestal, assim, as modalidades de certificações que geram o certificado FSC são: manejo florestal (MF), manejo florestal e cadeia de custódia (MF/CoC) e cadeia de custódia (CoC). $\mathrm{O}$ certificado de MF pode ser obtido por todos os produtores, sejam pequenos ou grandes, as florestas podem ser nativas ou plantadas, públicas ou privadas e pode ser dividida por tipo de produto, como, madeireiros e não madeireiros. O certificado 
de $\mathrm{CoC}$ aplica-se aos produtores que processam a matéria-prima proveniente das florestas certificadas, logo, o certificado $\mathrm{MF} / \mathrm{CoC}$ garante que o empreendimento produz e processa a matéria-prima certificada (FSC , 2017),

Segundo o FSC (2017), atualmente o Brasil possui aproximadamente sete milhões de hectares certificados na modalidade manejo florestal, além de mais de 1.000 certificados de cadeia de custódia. Assim, tomando conhecimento do número expressivo do Brasil dentro do sistema de certificação FSC, é importante conhecer em quais regiões do país estão concentrados os certificados, além de identificar quais modalidades estão presentes em maior concentração em cada localidade e as áreas certificadas dentro da modalidade manejo florestal. Nesse contexto, o presente trabalho, objetivou determinar a quantidade de certificados FSC no Brasil e a distribuição espacial, visando quantificar os certificados de manejo florestal, de manejo florestal com cadeia de custódia e de cadeia de custódia para empreendimentos que possuem essas modalidades de certificação florestal.

\section{MATERIAL E MÉTODOS}

\section{Base de dados}

Por meio do portal eletrônico do FSC, foram obtidos os relatórios de vistoria dos empreendimentos certificados em manejo florestal (MF), bem como os certificados de cadeia de custódia (CoC). Esses relatórios foram divididos em empreendimentos certificados com MF, CoC e ambos. Cada uma das modalidades de certificação tiveram todos os empreendimentos listados e os relatórios de todas as vistorias realizadas. Logo, foram obtidos os relatórios das vistorias mais atuais.

Os dados obtidos dos relatórios foram: nome do empreendimento certificado, cidade e estado onde o empreendimento está instalado, validade do certificado, natureza do certificado (MF, MF/CoC, CoC). Adicionalmente, para certificados de manejo florestal, além dos citados anteriormente, foram obtidos as áreas e os tipos de floresta, como nativa ou plantada.

\section{Quantificação e mapeamento}

Para a elaboração dos mapas, foram obtidos os códigos de cada município brasileiro no portal eletrônico do Instituto Brasileiro de Geografia e Estatística (IBGE) e, posteriormente, anexados na tabela com os dados obtidos nos relatórios. Esse procedimento possibilitou ao sistema de informações geográficas gerar mapas por meio da área certificada em manejo florestal por município ou da quantidade de certificados de cadeia de custódia por municípios. Dessa forma, foram gerados três mapas, sendo de MF, MF/CoC e CoC com o auxílio do programa computacional ArcGIS.

\section{RESULTADOS E DISCUSSÃO}

\section{Quantificação dos certificados FSC por região do Brasil}

Ao todo, pode-se constatar 1.099 certificados FSC atualmente no Brasil, sendo, seis para MF, 110 para MF/CoC e 983 para CoC. Desses, observou-se que a maioria encontra-se nas regiões Sul e Sudeste do país (Figura 1). Destacando o estado de São Paulo, que detém 516 certificados, sendo aproximadamente metade dos certificados FSC no Brasil. 


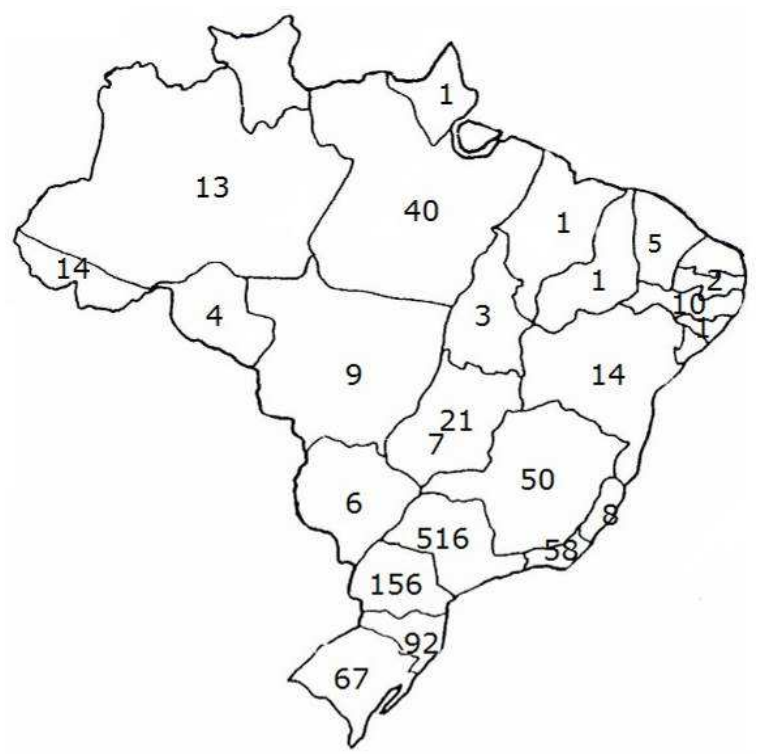

FIGURA 1 Quantificação dos certificados FSC no Brasil.

Os números de certificados por região do Brasil são, respectivamente para as regiões Norte, Nordeste, Centro-Oeste, Sudeste e Sul, iguais a $75(6,8 \%), 34(3,1 \%)$, $43(3,9 \%), 632(57,5 \%)$ e $315(28,7 \%)$ (Figura 2). A maioria dos certificados do estado de São Paulo correspondem a modalidade CoC, o que justifica-se pela concentração de indústrias, uma vez que é o estado mais desenvolvido do país, sendo responsável por mais de $33 \%$ do produto interno bruto brasileiro (EGLER; TAVARES, 2014; GIORGETTI, 2016).

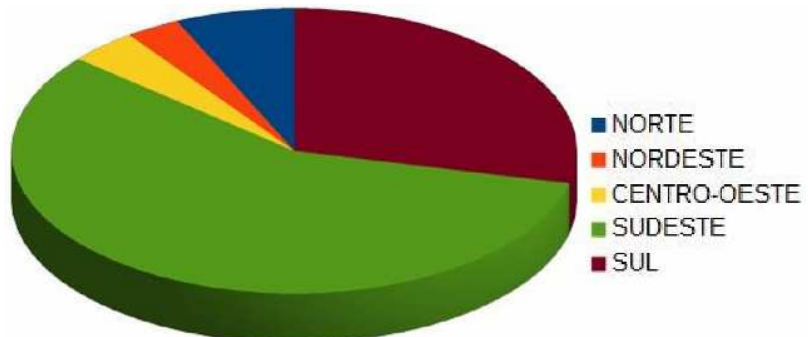

FIGURA 2 Quantificação dos certificados FSC por região do Brasil.

Foram observados 505 certificados na modalidade $\mathrm{CoC}$, sendo a maioria de e gráficas, editoras e impressões $(61,6 \%)$. Em seguida, o setor de papel, papelão e embalagens representam $20,4 \%$, ao passo que o setor de fabricação e comércio de móveis correspondem a $7,7 \%$. Por fim, os demais certificados (10,3\%) são relacionados à empreendimentos de marcenarias, painéis, processamento e comércio de madeira (Figura 3).

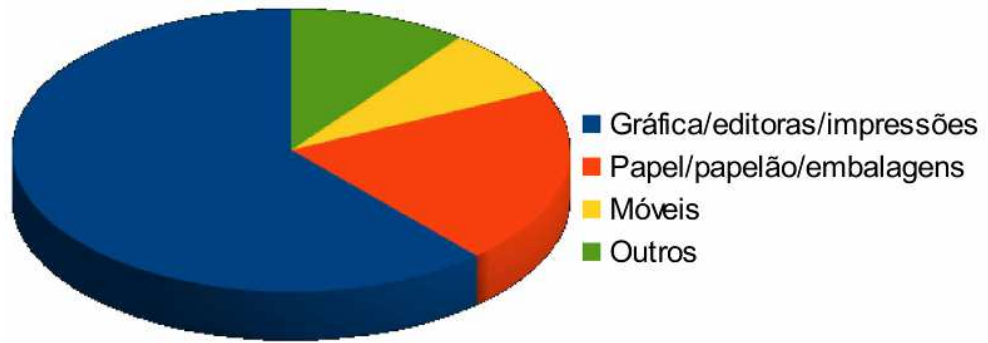

FIGURA 3 Quantificação dos certificados FSC de cadeia de custódia por tipos de empreendimentos no estado de São Paulo. 
A ausência de certificados nos estados de Roraima, Rio Grande do Norte e Sergipe foi outro dado relevante. De acordo com Cunha et al. (2009), a madeira é o principal produto de exportação de Roraima, porém, as madeireiras estão localizadas próximas aos bairros residenciais, o que têm causado transtornos ambientais e à saúde dos moradores vizinhos. Por outro lado, o estado do Amapá possui apenas um certificado referente a empresa Amcel Amapá Florestal e Celulose S.A., sendo na modalidade MF/CoC de floresta plantada, pois o estado ainda possui mais de $90 \%$ dos ecossistemas naturais intactos.

$\mathrm{Na}$ região Norte do Brasil, os certificados de manejo florestal são compostos na maioria por florestas nativas. Segundo Juvenal e Mattos (2002), os produtores brasileiros enfrentam restrições no mercado mundial, principalmente para aqueles de origem tropical baseadas em acusações de desmatamento da Amazônia. Cinco certificados são de certificações em grupo, o que, segundo FSC (2017), é uma alternativa para que comunidades e proprietários de pequenas áreas de manejo florestal se reúnam em grupos e juntos apliquem um único processo de certificação.

No estado do Pará está situado mais que 50\% dos empreendimentos certificados da região Norte. Dos 40 certificados do estado, um é da modalidade de MF, 12 de MF/CoC, e 27 de CoC. Dos certificados MF e MF/CoC, quatro são de florestas plantadas e nove de florestas nativas em 440.439,63 hectares. Assim, 0 estado do Pará detém a maior quantidade de florestas nativas certificadas, o que demonstra o potencial do estado para o manejo florestal sustentável (ROMA; ANDRADE, 2013).

A região do Nordeste apresenta o menor número de certificados, com destaque para os estados da Bahia e Pernambuco com mais certificados. No estado da Bahia, estão localizadas grandes empresas de celulose, como a Suzano e a Veracel, que apresentam áreas certificadas de plantios de Eucalyptus sp. Há também a certificação de plantios da Associação dos Produtores de Eucalipto do Extremo Sul da Bahia (ASPEX), de outro grupo de produtores florestais integrados e de outros plantios motivados pela instalação das papeleiras na região. Além dos certificados de CoC dessas empresas, há outras comerciantes de papel e gráficas, o que totalizam 14 certificados no estado da Bahia. No estado de Pernambuco, há exclusivamente certificados da modalidade $\mathrm{CoC}$ para indústrias e comércios de papel e gráficas.

No Sul e Sudeste, as indústrias mais capitalizadas têm investido recursos significativos na aquisição de florestas plantadas, de novas áreas para reflorestamento e de novos plantios. Atualmente, cerca de $80 \%$ das florestas plantadas são de pinus e de eucalipto, sendo os povoamentos de eucalipto localizados, em sua maior parte, na região Sudeste e no estado da Bahia. O pinus possui $76 \%$ de seus plantios nas regiões Sul e Sudeste do país (JUVENAL; MATTOS, 2002).

$\mathrm{Na}$ região Sul, estão presentes 53 certificados nas modalidades MF e $\mathrm{MF} / \mathrm{CoC}$ de florestas plantadas e um de floresta nativa, sendo esse referente a uma ervateira no Rio Grande do Sul. São 22 certificados de MF e MF/CoC na região Sudeste. Também, são 260 certificados de CoC na região Sul e 610 no Sudeste. O grande número de certificados presentes nas regiões Sul e Sudeste deve-se a vocação florestal, além de produzirem florestas plantadas.

O estado do Paraná é o segundo com mais certificados florestais no Brasil, em que, dos 156 certificados, 25 estão relacionados ao manejo florestal (MF ou $\mathrm{MF} / \mathrm{CoC}$ ), sendo todos de florestas plantadas, o que totaliza uma área de 766.720,16 hectares. Na modalidade CoC, a diferença da quantidade de certificados 
dos empreendimentos de gráficas, editoras e impressões não é expressivamente maior que de outros empreendimentos (Figura 4), representando 37 certificados $(28,2 \%)$; seguido pelos de papel, papelão e embalagens, com 20 certificados (15,3\%); de produção e comércio de móveis, com 14 certificados (10,7\%); de produção e comercialização de painéis de madeira, com 25 certificados $(19,1 \%)$; de comércio de madeira, como madeireiras, serrarias e venda de madeira tratada e serrada, com 26 certificados (19,8\%); e outros relacionados à marcenaria, empresas produtoras de celulose, comércio de portas, indústria de molduras $(6,9 \%)$.

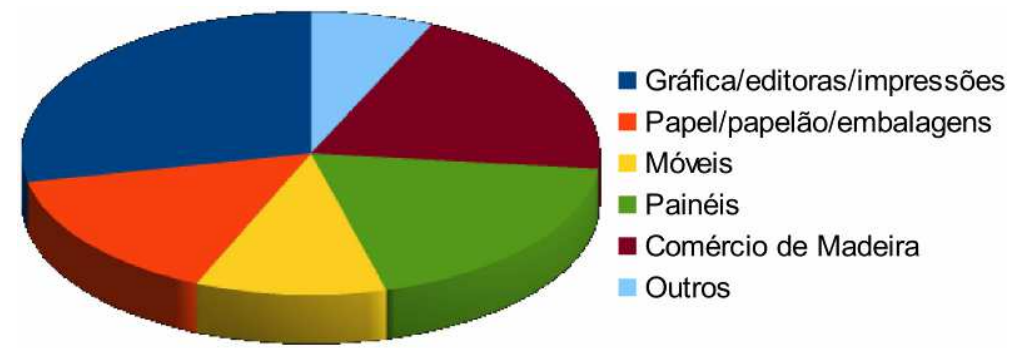

FIGURA 4 Quantificação dos certificados FSC de cadeia de custódia por tipo de empreendimento no estado do Paraná.

O Paraná é o estado com mais certificados de MF e MF/CoC para florestas plantadas, totalizando 25 certificados. Em segundo lugar está Santa Catarina, com 18 certificados, seguido de São Paulo com 11 certificados, Rio Grande do Sul com 10, Bahia e Minas Gerais com oito certificados cada, Mato Grosso do Sul com cinco certificados, Pará com quatro, Mato Grosso com três e Amapá, Espírito Santo e Maranhão com um certificado cada.

Na região Sudeste, o destaque se dá ao estado de São Paulo, seguido por estado do Rio de Janeiro, com 58 certificados de CoC, enquanto Minas Gerais possui 50 certificados, sendo 10 das modalidades MF e MF/CoC, dois de florestas nativas e oito de plantações. Os dois certificados de florestas nativas presentes em Minas Gerais são referentes a extração de óleos essenciais, sendo um estado com vocação natural para atividades florestais, fruto de amplo domínio tecnológico e técnico na formação de florestas de alto rendimento; condições de clima e solo apropriadas; disponibilidade de áreas antropisadas e existência de empreendimentos nas áreas de celulose, painéis de madeira, móveis, energia de biomassa florestal e siderurgia a carvão vegetal.

\section{Certificados FSC de manejo florestal por município}

$\mathrm{Na}$ modalidade certificação de manejo florestal (MF), foram encontrados apenas seis no Brasil situados nos municípios de Araucária/PR, Bréu Branco/PA, Guarapuava/PR, Itapeva/SP, Rio Negro/PR e Pirapora/MG (Figura 5). 


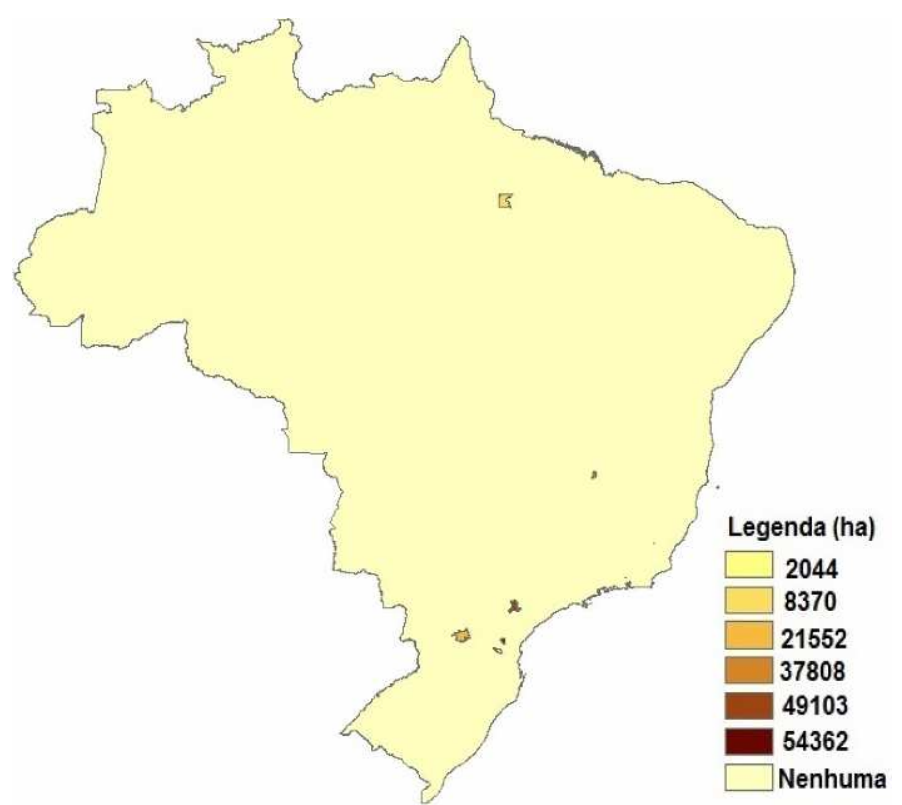

FIGURA 5 Distribuição dos certificados FSC de manejo florestal no Brasil.

As empresas certificadas na modalidade manejo florestal são: Berneck em Araucária, Palmyra Recursos Naturais Exploração e Comércio Ltda. em Bréu Branco, Reflorestadora São Manoel Ltda. em Guarapuava, Marquesa S.A em Itapeva, Madem S.A. em Rio Negro e TTG Brasil Investimentos Florestais Ltda. em Pirapora. Notou-se que todos os empreendimentos são de florestas plantadas, em que a Berneck e a Madem são empresas verticalizadas que possuem outras certificações para seus produtos, ao passo que as demais empresas trabalham exclusivamente com reflorestamentos.

\section{Certificados FSC de manejo florestal com cadeia de custódia por município}

$\mathrm{Na}$ modalidade manejo florestal com cadeia de custódia (MF/CoC) da certificação FSC, foram observados 110 certificados no Brasil. Os municípios com mais certificados nessa modalidade são: Caçador/SC, Telêmaco Borba/PR, Eunápolis/BA e Jaguariaíva/PR, com seis, cinco, três e três certificados, respectivamente. Percebeu-se maior quantidade de certificados nas regiões Sul e Sudeste, porém, nos municípios do Norte, a área de manejo certificada é maior, por serem de florestas nativas (Figura 6). 


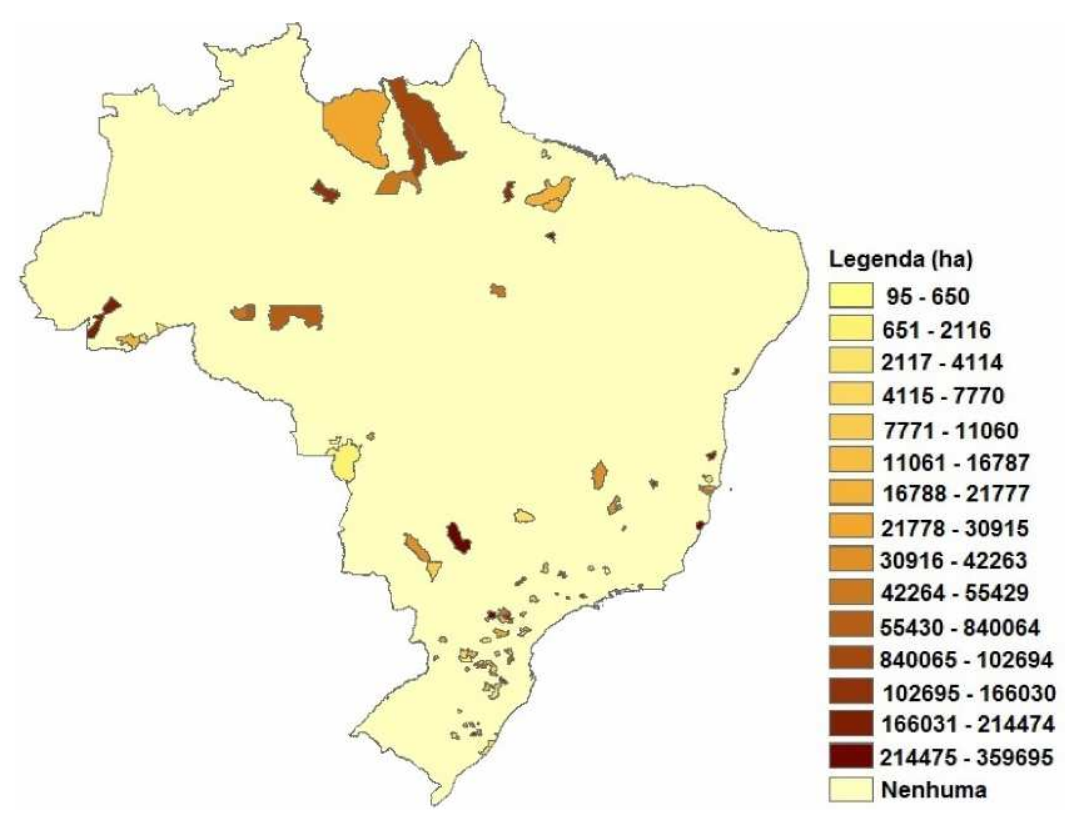

FIGURA 6 Distribuição dos certificados FSC de manejo florestal com cadeia de custódia no Brasil.

O município de Caçador, além dos seis certificados na modalidade MF/CoC, apresenta mais 10 certificados de CoC. Esse destaque deve-se a presença de madeireiras e de reflorestadoras instaladas no município. Segundo IBGE (2016), são produzidos $600.429 \mathrm{~m}^{3}$ de madeira de Pinus sp. e Eucalyptus sp. para diferentes finalidades, sendo Eucalyptus sp. exclusivamente para lenha e Pinus sp. para toras, celulose, entre outros. A madeira sempre foi a principal fonte econômica na região. A partir de suas próprias florestas, as indústrias do município produzem madeira serrada, celulose, papel/papelão, mobília, entre outros derivados.

No município de Telêmaco Borba, onde há uma unidade da Klabin S.A., além de quatro certificados de MF/CoC apresenta mais 18 de CoC. Segundo Silva et al. (2011), a Klabin promove indiretamente o desenvolvimento do município ao estimular outras atividades, mas Telêmaco Borda depende culturalmente da empresa para condicionar o desenvolvimento local. A partir da década de 1990, o mercado de papel e celulose tornou-se mais competitivo e a empresa teve que se adequar aos padrões do sistema internacional certificação florestal FSC.

O município de Eunápolis destaca-se pela instalação da Veracel Celulose S.A., que detém os certificados na modalidade MF/CoC e CoC, enquanto os outros dois certificados de MF/CoC são de associações de produtores de Eucalyptus sp., impulsionados também pela presença da papeleira no município. Em Jaguariaíva, os três certificados de $\mathrm{MF} / \mathrm{CoC}$ são de reflorestadoras, além de outros três exclusivamente de $\mathrm{CoC}$, referentes a uma madeireira, uma empresa de papel e uma de painéis. A fábrica da Arauco S.A. é um dos empreendimentos presentes no município.

\section{Certificados FSC de cadeia de custódia por município brasileiro}

Dentre os certificados de CoC, destacam-se os municípios de São Paulo/SP, Rio de Janeiro/RJ, Curitiba/PR e Guarulhos/SP, com 209, 38, 29 e 26 certificados, respectivamente. A maioria dos municípios que apresentam algum certificado de manejo possui entre um e três certificados (Figura 7). Nota-se também que a maior quantidade de certificados CoC estão nas regiões Sul e Sudeste. 


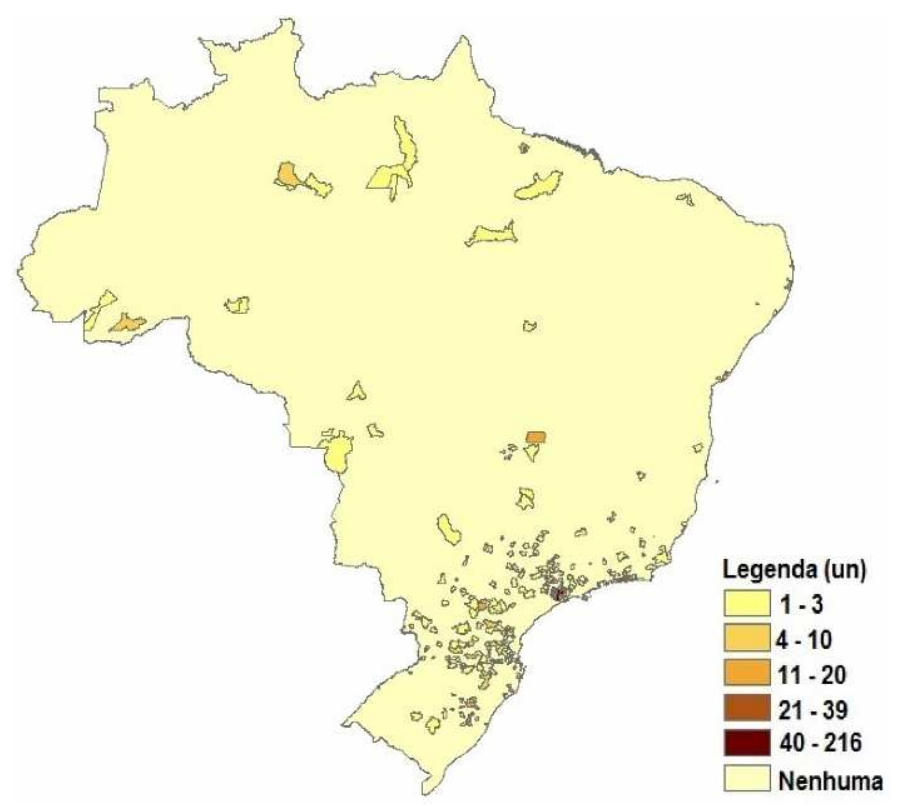

FIGURA 7 Distribuição dos certificados FSC de cadeia de custódia no Brasil.

A cidade de São Paulo detém 209 certificados de CoC. Desses, 32 são referentes a empreendimentos de papel e papelão (15,3\%); 151 de gráficas, editoras e impressão (72,2\%); 9 de empreendimentos de confecção e comércio de móveis $(4,3 \%)$; três de marcenarias $(1,4 \%)$; quatro de fabricantes de celulose $(2 \%)$; e 10 de empreendimentos que comercializam madeira (4,8\%) (Figura 8).

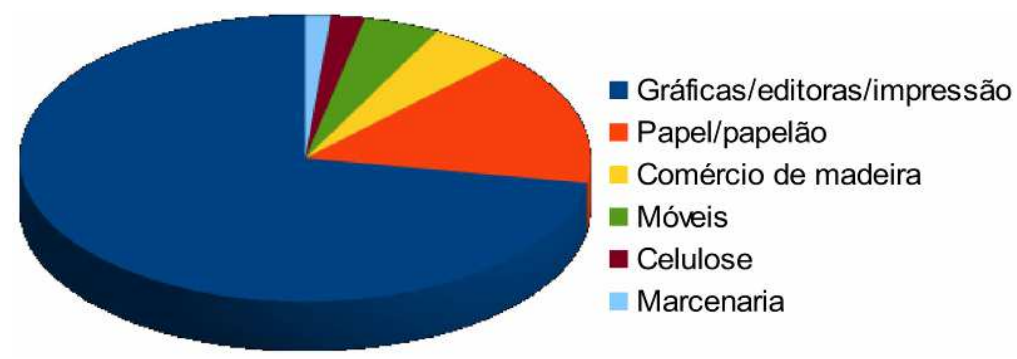

FIGURA 8 Quantidade de certificados FSC de cadeia de custódia por tipo de empreendimento no município de São Paulo.

Dos 98 certificados de CoC da cidade do Rio de Janeiro, apenas cinco não são de gráficas e editoras, concluindo que as certificações são referentes a origem do papel utilizado. Ademais, nos municípios de Curitiba e Guarulhos, a maioria dos certificados também são referentes as gráficas e editoras. Assim, constatou-se que a distribuição espacial dos certificados FSC no Brasil é desuniforme, onde há áreas com poucos ou nenhum certificado, por serem áreas em que a atividade florestal é pouco desenvolvida.

O foco para a expansão da certificação é importante nas regiões que desenvolvem atividades florestais, porém a certificação é pouco utilizada, seja, por falta de uma grande empresa que influencie as atividades econômicas e que demonstre a importância do selo verde, seja por pressão dos compradores para com a sustentabilidade, ou pelo desenvolvimento econômico da área em volta das 
atividades florestais e madeireiras que impulsionam o conhecimento de novas táticas de mercado para diferenciação do produto.

Dessa forma, recomenda-se maior divulgação da Certificação Florestal pela terceira parte. Para a expansão das outras regiões do Brasil, além do Sul e do Sudeste, e melhorar o marketing para os compradores, para maior exigência de produtos certificados. Um exemplo é o estado de Roraima, onde não há nenhum certificado, porém, a madeira é o principal produto de exportação, é provável que há ausência de sensibilidade e de conhecimento dos empresários sobre a certificação. Com isso, a certificação florestal FSC pode gerar oportunidades e abrir mercados aos produtores.

\section{CONCLUSÕES}

Existem 1.099 certificados FSC no Brasil, distribuídos em três modalidades, cuja quantidade de certificados por modalidade são 6, 110 e 983 para manejo florestal, manejo florestal com cadeia de custódia e cadeia de custódia, respectivamente.

As regiões do país com mais certificados são Sul e Sudeste, por serem regiões com vocação florestal e culturalmente desenvolvidas em torno das atividades florestais e madeireiras. Na região Sudeste, destaca-se o estado de São Paulo, onde a maioria dos certificados é da modalidade de cadeia de custódia.

O estado do Paraná é o que obtém mais certificados na região Sul, além de ser o segundo com mais certificados FSC do país, estando atrás apenas de São Paulo. Dos 156 certificados do Paraná, 25 são relacionados ao manejo florestal, exclusivamente de florestas plantadas.

Avaliando a quantidade de certificados por município, observou-se que os que apresentam maior quantidade de certificados de manejo florestal com cadeia de custódia são os que possuem empresas de grande porte do setor florestal. Elas impulsionam o desenvolvimento florestal no município e demonstram a importância de produzir de forma sustentável, utilizando o selo verde como marketing do negócio. Também são os municípios que se desenvolveram economicamente por meio do setor florestal e madeireiro.

Das certificações de manejo para florestas nativas destacam-se os municípios do estado do Pará, por ser o estado com maior atividade madeireira da Amazônia. As empresas que optam pelo certificado exclusivamente de manejo florestal são empresas de reflorestamento ou verticalizadas que possuem outras certificações florestais e ambientais para os seus produtos.

Dentro da modalidade cadeia de custódia, os municípios com mais certificados são: São Paulo/SP, Rio de Janeiro/RJ, Curitiba/PR e Guarulhos/SP. Assim, a certificação florestal FSC está diretamente relacionada com as empresas instaladas nas regiões, bem como com a vocação florestal, com o desenvolvimento cultural e com o conhecimento do mercado para produtos certificados.

\section{REFERÊNCIAS}

AHRENS, S.; OLIVEIRA, Y. M. M. Plantações florestais comerciais, a certificação e os diálogos setoriais. In: OLIVEIRA, Y. M. M. de; OLIVEIRA, E. B. de (Ed.). Plantações florestais: geração de benefícios com baixo impacto ambiental. Brasília: Embrapa, p. 73-78, 2017.

ALVES, R. R.; JACOVINE, L. A. G.; SILVA, M. L. Plantações florestais e a proteção de florestas nativas em unidades de manejo certificadas no Brasil. Revista Árvore, 
v. 35, n. 4, p. 859-866, 2011. Disponível em: $<w w w . s c i e l o . b r / p d f / r a r v / v 35 n 4 / a 11 v 35 n 4>$.

CUNHA, P. S. C.; SOUZA, R. B. L.; SOUZA, P. L. Análise do setor madeireiro de Roraima e sua interação com a contabilidade ambiental e o desenvolvimento sustentável. ConTexto, v. 9, n. 15, 2009. Disponível em: <http://seer.ufrgs.br/index.php/ConTexto/article/view/11331>.

EGLER, T. T. C.; TAVARES, H. M. Política pública, rede social e território. Rio de Janeiro: Letra Capital, 2014. 325 p.

FSC - Forest Stewardship Council. Florestas para todos sempre. 2017. Disponível em: <https://br.fsc.org/pt-br>.

GIORGETTI, C. Outras crônicas. São Paulo: Clube de Autores, 2016. 95 p.

IBGE - Instituto Brasileiro de Geografia e Estatística. Produção da Extração Vegetal e da Silvicultura 2015. Rio de Janeiro: IBGE, 2016. Disponível em: $<$ https://cidades.ibge.gov.br/xtras/temas.php?lang=\&codmun=420300\&idtema=160\& search=santa-catarina|cacador|extracao-vegetal-e-silvicultura-2015>. Acesso em: 01 out. 2017.

JUVENAL, T. L.; MATTOS, R. L. G. O setor florestal no brasil e a importância do reflorestamento. BNDES Setorial, n. 16, p. 3-29, 2002. Disponível em: <https://web.bndes.gov.br/bib/jspui/handle/1408/3142>.

PAIVA, S. N.; SILVA, D. A.; ROCHADELLI, R.; HOSOKAWA, R. T.; OSHIRO, C. R. A certificação florestal pelo FSC®: um estudo de caso. Floresta, v. 45, n. 2, p. 213 222, 2015. Disponível em: <http://dx.doi.org/10.5380/rf.v45i2.30055>. doi: 10.5380/rf.v45i2.30055

PEREIRA, L. C.; PELISSARI, A. L.; SANQUETTA, C. R.; EBLING, A. A. Estudo de caso da adequação de uma serraria às normas FSC de cadeia de custódia. BIOFIX Scientific Journal, v. 2, n. 1, p. 7-15, 2017. Disponível em: <http://dx.doi.org/10.5380/biofix.v2i1.50274>. doi: 10.5380/biofix.v2i1.50274

ROMA, J. C.; ANDRADE, A. L. C. Economia, concessões florestais e a exploração sustentável de madeira. IPEA - Boletim regional, urbano e ambiental, v. 8, p. 9196, 2013. Disponível em: <repositorio.ipea.gov.br/handle/11058/5614>.

SANQUETTA, C. R.; CORTE, A. P. D. Certificação florestal. Curitiba: UFPR, 2012. $71 \mathrm{p}$.

SILVA, H. P.; SILVA, C. L.; ANDREOLI, C. Atividade econômica de celulose e papel e desenvolvimento local: a história da Klabin e do município de Telêmaco Borba. Interações, v. 12, n. 2, p. 137-148, 2011. Disponível em: <http://dx.doi.org/10.1590/S1518-70122011000200002>. doi: 10.1590/S151870122011000200002

VIEIRA, H. D.; MELO, J. B. A certificação FSC: estudos de casos no setor moveleiro AGRARIAN ACADEMY, Centro Científico Conhecer - Goiânia, v.4, n.8; p.238 2017 
em Fortaleza - Ceará. Revista Encontros Universitário da UFC, v. 2, n. 2, p. 664, 2017. Disponível em <http://www.periodicos.ufc.br/eu/article/view/25687>. 